\title{
Evaluación del Boletín Médico del Hospital Infantil de México por el Comité de Revisión Técnica para Selección de la Literatura de la Biblioteca Nacional de Medicina
}

\author{
Evaluation of the Boletín Médico del Hospital Infantil de México by the Literature Selection \\ Technical Review Committee of the National Library of Medicine
}

\section{María Guadalupe Campos-Lara}

Editora, Boletín Médico del Hospital Infantil de México; certificada por la Universidad de Chicago, EE.UU. graduada del Publishing Training Centre, Londres, Reino Unido; miembro internacional en las oficinas editoriales del Journal of the American Medical Association

Evaluar... evaluar... La evaluación, entre otras definiciones, cuenta con la de «recoger y analizar sistemáticamente información para determinar el valor o mérito de lo que se hace». Evaluar toda actividad humana es consustancial a la propia naturaleza del hombre. Evaluar gobiernos, salud, educación, artes, instituciones, organizaciones, empresas, aquello y lo otro, y claro, evaluar la actividad científica de los investigadores, sus proyectos, sus artículos, su «productividad» y hasta las revistas donde publican sus resultados. ¿Por qué? ¿Para qué? ¿Cómo?

El 7 de noviembre de 2017 llegó un correo a la dirección electrónica del Boletín Médico del Hospital Infantil de México (BMHIM), anexando la carta del Director Asociado de Operaciones de la Biblioteca Nacional de Medicina de los EE.UU., con asunto BMHIM, en cuyo primer párrafo se lee: «The National Library of Medicine (NLM) uses an NIH-chartered advisory committee, the Literature Selection Technical Review Committee (LSTRC), to recommend journals to be indexed for MEDLINE®. At the recent LSTRC meeting, the committee recommended your journal for MEDLINE®. MEDLINE® citations are indexed with NLM Medical Subject Headings (MeSH®) and other metadata, and are searchable as a subset of PubMed®».
Primeramente, alegría. ¡Gran alegría! Se cerraba la brecha existente desde diciembre de 1993, última vez que el BMHIM había aparecido en MEDLINE®. A continuación, la participación a las autoridades de nuestro instituto, al personal del Departamento de Ediciones Médicas... Inmediatamente después, agradecimiento; posteriormente, reflexión...

Agradecimiento principalmente a los autores que, desde julio de 2014, y antes, han enviado sus trabajos a nuestra revista. A los revisores, sin cuya gratuita y sesuda labor no se erige uno de los principales pilares de una revista académica: la evaluación del contenido científico por colegas externos y pares del campo en cuestión. A los miembros del consejo y del comité editorial que sí han colaborado con el BMHIM. A las autoridades del Hospital Infantil de México Federico Gómez que han apoyado incondicionalmente el desarrollo de nuestra revista. A los traductores. A las casas editoriales que nos han publicado. A las editoras.

Reflexiones... Cabe mencionar algunas: ¿qué fue lo que evaluó el LSTRC de nuestra revista? El cumplimiento estricto de la periodicidad de la publicación de la versión electrónica en español (ISSN 1665-1146), también disponible en inglés; la calidad del contenido de los artículos, incluyendo autores e instituciones; la
Correspondencia:

*María Guadalupe Campos-Lara

E-mail: bolmedhospinfantmex@gmail.com
Disponible en internet: 02-03-2018 Bol Med Hosp Infant Mex. 2018;75:5-6 www.bmhim.com

1665-1146/@ 2018. Hospital Infantil de México Federico Gómez, impreso por Permanyer México SA de CV, todos los derechos reservados. 
calidad de la revisión externa de pares. Asimismo, que todas las políticas éticas se cumplieran: declaración de conflictos de intereses, derechos animales y humanos, y consentimiento informado cuando procede.

¿Cuáles son los resultados inmediatos de haber sido indexados en MEDLINE $®$ ? Aumento de la visibilidad por los usuarios y científicos del área de la salud que tienen acceso a PubMed®: prácticamente 180 países con internet de los 195 reconocidos en la Organización de las Naciones Unidas. Visibilidad desde finales del 2016, y probablemente incremento de la citación de los trabajos publicados en BMHIM.

¿Cuáles son las acciones inmediatas que hay que tomar? Por sugerencia del LSTRC, abrir las puertas a más colaboraciones con países de América Latina y no restringirse a investigaciones realizadas en México; aumentar el rigor del proceso de revisión por pares, así como reducir la tasa de aceptación de artículos: todo converge en la calidad de las revistas.

Seguimos satisfechos de que BMHIM también esté indexado en Scielo, Scopus, Emerging Sources Citation Index, DOAJ, Latindex, EMBASE, WorldCat y EBS$C O$, además de que sea una revista de libre acceso.

¿Cuáles son las acciones mediatas que hay que tomar? Parecería evidente seguir en la carrera de la indexación de las revistas académicas: Journal Citation Reports, Research Gate y los nuevos factores de impacto que surjan. Seguramente haremos un esfuerzo en beneficio de los autores y de sus evaluaciones curriculares. Sin embargo, esta sería la respuesta a la inercia de procedimiento en las revistas académicas. La tarea que espera a los editores responsables del desarrollo de "sus» revistas es ardua y toma tiempo: lograr la indexación en Web of Science y acumular numerosas citas en otras prestigiosas revistas, y promover a sus autores y artículos a una amplia audiencia. El clásico Journal Impact Factor sigue siendo una influyente métrica de citación, aunque no es la única, y su validez está en tela de juicio. Actualmente se tiene en duda cuán necesario es y si ha sido apropiadamente usado por instituciones y gobiernos como medida de calidad y prioridad de los artículos científicos ${ }^{1}$. Como resultado de ello, en los años recientes, la Sociedad Americana de Biología Celular expidió el documento San Francisco DORA (Declaration On Research Assessment) para reconocer la necesidad de mejorar las diferentes maneras en que los resultados de la investigación científica son evaluados ${ }^{2}$. Poco después, la Liga de Universidades de Investigación Europeas se adhirió a dicha declaración ${ }^{3}$.

Evaluar... ¿Por qué? ¿Para qué? ¿Cómo? La evaluación se ha constituido históricamente en un instrumento de selección y control. Con ella se intenta concretar formas de control individual y su extensión a formas de control social ${ }^{4}$. ¿Dónde ha quedado la confianza en la genuina generación del conocimiento científico? ¿Cuál sería, entonces, una manera más equilibrada de evaluar la labor de los investigadores?

\section{Bibliografía}

1. Hong ST, Gasparyan AY. Celebrating the latest release on the journal impact factors: thinking globally, acting locally. J Korean Med Sci. 2015;30:999-1000.

2. American Society for Cell Biology. San Francisco Declaration on Research Assessment. 2012, December 16. (Consultado el 21 de enero de 2018.) Disponible en: https://sfdora.org

3. Philips M. Research universities and research assessment. (Consultado el 21 de enero de 2018.) Disponible en: https://www.leru.org/files/Research-Universities-and-Research-Assessment-Full-paper.pdf

4. Rosales M. Proceso evaluativo: evaluación sumativa, evaluación formativa y su impacto en la educación actual. Congreso lberoamericano de Ciencia, Tecnología, Innovación y Educación. Buenos Aires, Argentina; 2014. Artículo 662. 